\title{
Engaging Social Media for Health Communication in Africa: Approaches, Results and Lessons
}

\section{Adebayo Fayoyin*}

UNFPA, Johannesburg

\begin{abstract}
Advancements in digital media and communications technology have generated considerable optimism on the role of social media in achieving developmental and public health outcomes globally. The unprecedented availability of digital devices and platforms has also prompted different development institutions to design and implement a range of social media interventions for social and behaviour change. This paper examines how social media are transforming health communication in Africa. Our study demonstrates the existence of an avalanche of interventions using different mobile devices and mobilization approaches in addressing multiple health issues. The interventions target different population groups and are not limited to young people who are considered as the major users and consumers of social media content. However, the study cautions against "new media utopianism" or "social media-centricism" because technology is a tool of development not an end in itself. It recommends strategies for effective deployment of social media in health communication including applying a theory of change model, creative integration of multimedia platforms and meaningful participation of all actors to generate a new development narrative. Implications for health communication's theory, practice, policy, research and training are also addressed.
\end{abstract}

Keywords: Digital media; E-Health; Social change; Health communication

\section{Introduction}

Africa's health burden is still currently high, requiring (among other strategies) the application of innovative communication approaches in achieving the continent's public health agenda. The outbreak of Ebola in 2014, which killed over 11,000 people in at least five countries [1] is a sad reminder of the continent's unending susceptibility to epidemics. HIV is still ravaging different communities and population groups, despite the deployment of multiple advocacy tactics by the AIDS fraternity in the last 30 years [2,3]. In addition, over 50 per cent of women who die from pregnancy-related causes, and at least 30 percent of under-five deaths among new-borns, occur on the continent [4]. Although Africa has only 13 per cent of the World population, it carries 24 per cent of the global health burden [5].

Communication is central to public health delivery, and advances in digital media and communication technology hold significant prospects for addressing major public health and development issues confronting the continent. Such optimism is grounded in the increasing levels of internet penetration as well as intrinsic characteristics of social media which include interactivity, genuine dialogue, speed, multimodality, user-generated content, mass customisation, horizontal communication, and multi-directionality of information [6,7]. Other studies have also underscored the significance of information and communications technologies in transforming health communication practices $[6,8,9]$.

Therefore, this paper examines the utilisation of social media for health communication in Africa. It builds on previous studies $[7,10,11]$ on the use of social media for health communication at the global level. The paper outlines the promise of social media in health communication and the major limitations of their application followed by five illustrative case studies on the deployment of social media for specific health issues. The cases are not intended as a comprehensive evaluation of the interventions, rather as an attempt to expound the emerging patterns.

From the analysis, the paper recommends that health related social media interventions should be grounded in a theory of change, enhance meaningful participation of critical actors in the development process, and address the problem of inequities. In addition, health communication programmers need to ensure the strategic harmonisation of social media interventions in line with specific national health agenda and programmes for synergistic implementation, and not as fragmentary and uncoordinated branded interventions of individual aid agencies. Finally, increased attention is needed for the sustainability of the flurry of social media interventions to avoid a situation where the development landscape in Africa is dotted with unsustainable 'white elephant' E-Health communication projects.

\section{The Global Context: The Shift Toward E-Health Communication}

There is currently a global recognition of the power of digital media in transforming various sectors of society, especially public health delivery. Advances in digital technology have resulted in the application of new media technologies for diverse health problems [1215]. However, this paper focusses on the use of digital media for health communication purposes, which is sometimes referred to as E-Health communication.

As argued in [12], the use of electronic communication for health purposes predates current advances in digital media. Early efforts to use information technology for health delivery involved didactic patient

*Corresponding author: Adebayo Fayoyin, Regional Communications Adviser UNFPA, East and southern Africa Region, Johannesburg, South Africa, Tel: 507 65618183; E-mail: fayoyin@unfpa.org

Received July 11, 2016; Accepted September 23, 2016; Published Septembe 26, 2016

Citation: Fayoyin A (2016) Engaging Social Media for Health Communication in Africa: Approaches, Results and Lessons. J Mass Communicat Journalism 6: 315 doi: 10.4172/2165-7912.1000315

Copyright: $\odot 2016$ Fayoyin A. This is an open-access article distributed under the terms of the Creative Commons Attribution License, which permits unrestricted use, distribution, and reproduction in any medium, provided the original author and source are credited. 
communication through websites, telemedicine, and participant-centre approaches such as blogs, wikies, mobile phones, emails and podcasts. Technologically-enabled solutions were also intended to provide alternative sources of information in the health sector, including sharing of data and creating opportunities for interaction among media personnel. Nevertheless, developments in internet technology and an unprecedented growth in mobile infrastructure have expanded the deployment of social media devices for health communication and education globally.

Social media platforms have now become indispensable for health literacy and an overall improvement of health outcomes [9]. Furthermore, some forms of E-Health interventions [16] include data collection and disease surveillance, health information management and point of care, treatment compliance and emergency response. Other areas of application include health information dissemination, health care monitoring, training of health care workers, tracking of disease outbreak and diagnostic support $[7,11]$.

In their study, [17] state that mobile telephony can reach more people with health information, facilitate interactivity, and promote confidentiality of use. Such transformative effect of mobile technology in health care in developing countries is affirmed by [18] as follows:

Mobile health is often described as a 'game-changing' technological platform. Unlike other mass communication platforms such as television and radio, mobiles cannot only be used to provide information and enable people to interact with that information, but also to deliver services and strengthen health systems. In other words, "mobile telephony can unite both the educational and clinical functions of mHealth in one device" [p.7].

Specifically on the role of digital technology for social marketing, [19] suggests that advancement in information technology offers major opportunities for health promotion in engaging health professionals with their patients, and the mobilization of new clients. The author hypothesises that the new media signals a shift in thinking about traditional methods of social marketing and communication for development. This assertion is consistent with [20] who contend that more than any other time in history, social media offers timely and credible health information, critical for improving public health outcomes quickly and directly.

Against the backdrop of the defining impact of computer and internet technologies [6] affirms that using social media for health communication will eliminate some of the inherent limitations of traditional health communication through improved customisation, contexuality, interactivity and mixed media utilisation. One could also argue that digitally enabled social media interventions such as mobile phones, instant messaging, chat room forums and social networking sites are also particularly relevant for communication of sexual and reproductive health issues.

Nevertheless, the use of social media for health communication is not without major challenges. From a broader perspective, it is argued that social media could potentially reinforce uneven disparities in society. It has also been suggested that due to the traditional NorthSouth digital divide, which indeed is a social, economic and cultural divide, ICT innovations may not considerably ameliorate the situation of the rural poor [21]. While some may argue that the discourse about the digital divide belongs to the moribund era of the New World Information and Communication Order (NWICO) in the 1980s, current evidence suggests that asymmetry in media access and reach exists in society today [22]. Specifically on economic impact, [23] demonstrates that mobile phones can result in 'informationalization of poverty' through the 'creation or recreation of economic disambiguation'. As an illustration, [24] mentions how users of new media in Ghana sometimes divert money meant for important family needs and welfare into buying airtime and expensive phones.

Researchers have also expressed serious concern over the use of mobile phones for health delivery, especially because of its embryonic infrastructural support. As a result, [18] posit that mobile telephony should not be considered a panacea for the health challenges of developing countries. Another study lists the following constraints on the use of mobile phones for health communication: cost, limited access to mobile phones, content restriction and limited personalisation of health information [17].

Furthermore, the digital context has substantial potential for health misinformation. Despite wide usage of the Internet for health information, [25] opines that it is also a source of massive misinformation. The conclusion is validated by [26] who have established specific instances of misinformation and circulation of incorrect health data nationally and internationally because of information agility and social connectivity of the digital age. This concern is further reinforced by [27] with respect to the impact of social media on young people. They submit that the Internet and social media can perpetuate misconceptions on sexual and reproductive matters for young people and can lure them into inappropriate platforms and content.

From the foregoing, it is argued that social and digital technology has great potential for transforming health education and communication globally. However, significant caution is necessary on its perceived impact within the pathway of social and behaviour change. Thus continuous lesson learning will be necessary on how to maximise the power of social media for public health communication [28].

\section{Case Studies}

The African continent has, in recent years, experienced significant progress and transformation in its digital technology systems. For instance, internet penetration in Africa has been described as 'phenomenal' and the emergence of mobile technology is generally perceived as the 'second communications revolution'. Specifically, [29] observes that "mobile phones made it possible for millions of Africans to make their first telephone calls ever". Digital solutions have been deployed for different sectors of society, including health education and communication. A host of country-specific and multi-country social media initiatives have been designed for addressing the multifaceted public health dilemmas confronting the continent [17,30,31]. To this end, an assessment by the World Health Organisation in 2012 concluded that besides scores of existing interventions, over 300 E-Health initiatives were being planned on the continent. And judging by the rapidity with which development agencies have been applying E-Health and social media technologies, the number of such interventions would have grown exponentially. In the following section, a brief description of five major digital health communication interventions is provided. Following the review, cross cutting issues and implications are discussed.

\section{Social Media for Health Education on Ebola Outbreak in Nigeria}

Nigeria was one of the West African countries affected by the Ebola outbreak in 2014. The discovery caused a global scare due to the 
populous nature of the country and the catastrophic consequences of a full blown epidemic for the global community [1]. Based on lessons from other countries in the region, effectively handling the crisis required massive education of both health workers and the public. With immense global support, the country instituted a coordinated response which curtailed the outbreak. In the end, only 20 people died compared to nearly 8,000 and 7,700 in Sierra Leone and Liberia respectively.

Many commentators have attributed the success of the response primarily to the impact of digital media. At the time, Nigeria had over 130 million mobile phone users and 67 million internet subscribers; and active social networks which played a significant role. In an article published in the high profile British Medical Journal, titled "How Twitter may have helped Nigeria contain Ebola", it is argued that targeted social media campaigns in Nigeria helped to disseminate accurate information about the disease and to correct hoax messaging [32]. Several Twitter handles were established, sharing regular information. UNICEF organised a campaign on Facebook which disseminated timely information and also deployed an army of U-reporters (a group of young people involved in an innovative youth participation programme) for information monitoring, reporting and sharing information with relatives and friends. To assist in making messages on the virus go 'viral', the World Health Organisation (WHO) and the Centre for Diseases Control (CDC) provided appropriate information on the situation nationally and internationally. Influential national bloggers and celebrities joined in the campaign for information blast on the virus, using their multiple platforms to educate their networks and constituencies.

Health workers also used a combination of Android Apps, Facebook, Twitter and Google Trends to identify topics of interest on the issue and communicate such to the public. An Ebola tutorial was developed by Vecna Technologies and Anadach Group and distributed by InStrat to health care workers across Nigeria [33]. This provided real time information on the causes of Ebola, its spread, diagnosis and treatment [17]. Another device used for the response was Ebola Alert, a technology-based organisation of volunteer doctors established to provide information on specific aspects of the outbreak and virus 24/7. Countless SMS platforms were used to circulate information on the signs and symptoms of Ebola. The International Federation of the Red Cross (IFRC) sent two million text messages each month about Ebola, providing the public with the much-needed information on screening, diagnosis and treatment [17]. Overall, the deployment of social media for accelerated and extensive information dissemination has been singled out as instrumental to the containment of the outbreak. However, critical questions need to be answered: How do we attribute specific success to social media in the process? Why has 'information blast' not created similar breakthroughs for other health pandemics like HIV or malaria or changed the behaviour on condom use in many countries? And if social media was pivotal to the success in Nigeria, why did it not perform the same magic in other countries? Answers to these questions (and many other related ones) will provide more insightful understanding of the impact of social media on the Ebola outbreak in Nigeria.

\section{Social Media for Group Communication on HIV with Men Who have Sex with Men (MSM) in Ghana}

According to Ghana's HIV epidemiological profile, men who have sex with men (MSM) constitute a major group to be addressed in tackling the HIV pandemic in the country. HIV prevalence among the group is 17.5 per cent while the overall national adult prevalence is only 1.3 per cent. Infection rates among this group are even higher in some districts, especially in Accra with 34.4 per cent. However, in view of the deep-rooted stigma associated with this sexual orientation in Ghana (as in many African countries), members of the group operate underground and are unable to access HIV services. It is also widely recognised that MSM in the country lack access to basic information about HIV transmission, including infection and prevention [30,34]. The traditional modes of information, education and communication, including targeted face-to-face outreaches are generally less effective as tools of engagement due to entrenched stigma and discrimination. However, studies in other parts of the world have established the relevance of social media for mobilizing and engaging with similar groups [35-37]. The studies concluded that social networking communities are more effective in targeted mobilisation of vulnerable populations and those perceived as high risk groups.

Against this backdrop, FHI360 initiated a social media campaign with MSM in 2013. The programme was aimed at building a relationship with them and sharing information via existing social media platforms, such as Facebook, Badoo and Grindr. Both official and closed Facebook pages were deployed in reaching and opening a conversation with the members. One-on-one interaction through identified social media platforms was integrated into the package of communication [38]. The expected outcome of the campaign was information sharing for group engagement, but also to promote conversation on specific issues and for increased uptake of necessary services [30].

As findings from the programme demonstrated, 15,440 unique MSM were mobilised and many of them became more predisposed to seeking customised services [30]. However, traditional modes of engagement with MSM leaders - beyond social media platforms were integral to the intervention. Initial and ongoing face-to-face consultations were established with key influencers of the group. Thus even with the use of social media as the dominant tool, interpersonal communication was found to be appropriate for group mobilisation. According to [30] traditional outreaches also reached 12,804 MSM, which allowed the programme to cover over 90 per cent of MSM in the country.

From this case, it is argued the integration of the virtual and physical space, even in designing and implementing social media interventions for health communication was fundamental to the results attained. In this case as well, it would be difficult to arrogate any 'uber effect' solely to social media.

\section{Mobile Phones for Polio Campaign in Somalia}

Somalia, in the Horn of Africa, is one of the countries in the polio epidemic belt. The country was certified polio free in 2006, but new cases of wild polio virus were detected in 2013, necessitating an intense social mobilisation campaign for its eradication [39]. Since the new outbreak, targeted immunization of the population and house-tohouse outreaches were implemented. Development partners in Somalia (Oxfam, UNICEF and Hijra, a local NGO) decided to experiment with the use of mobile phone technology for polio health promotion for two main reasons. First, the political situation has continued to make most of the population hard-to-reach due to insecurity. Nonetheless, the country is experiencing an increasing penetration of mobile phones, making targeted information sharing much easier. As a result, the agencies designed a new mobilisation strategy with mobile phone technology as the major tool of communication on polio immunization.

The initiative involved the use of pre-emptive community education 
through mobile phones. The education component comprises four interactive daily SMS sessions intended to reach 100,000 people in 17 districts. It also includes distribution of non-food items as an incentive scheme for promoting adherence to immunization schedule through an mVoucher mobile system [31].

An evaluation of the project concluded that the polio education component reached 104,358 people, much higher than the expected target. However, due to logistical challenges, the mVouchers system achieved only 50 per cent of its target. The evaluation suggests that the project has the possibility of being a game changer for polio education and conditional distribution of incentive scheme [31]. But it also argues that 'novelty factor' might have been responsible for high service uptake. As a result of the numerous intervening variables in the programme design and implementation, it is difficult to attribute the high uptake of polio immunisation directly to the mobile information dissemination. To be clear, the incentive scheme of non-food items and the novelty of digital media might have played a critical role in the programmes results. This again demonstrates the need for a robust investigation of the impact of the various variables in programme delivery in order to isolate cross cutting, compounding or mutually reinforcing variables in health communication.

\section{Mobile Phones for Maternal Health Education in South Africa}

The problem of maternal health in South Africa has attracted substantial public and media interest. 4,300 mothers die every year in the country due to complications during pregnancy and childbirth. In addition, 20,000 still births are recorded annually while 23,000 die in the first month of life. Many of these deaths are preventable with effective health education and timely interventions.

In 2013, health and development partners established MAMA South Africa (a package of E-Health communication) to provide health awareness and information. This intervention disseminates culturally sensitive information to expectant mothers through mobile phones, via an SMS messaging service in five different languages and a social networking platform called MXit; a popular social media site in the country. Four channels of mobile communication - interactive website, text messaging, social networking, and voicemails are offered to clients [40].

The intervention includes a platform, Mom Connect, designed to link pregnant women and mothers to health care workers through mobile technology as well as an interactive question and answer portal. Critical health messages on pregnancy and child birth issues are sent on mobile phones to pregnant women and mothers registered in the scheme. For pregnant women, it incorporates stage-based health information on their pregnancy, and for mothers living with HIV it sends essential messages on their treatment updates [41,42].

The intervention also updates client medical records in real time for health workers to have adequate information on which services to provide. The personalised information dissemination programme has been recognised as an innovative approach to client communication. Timely health messages made available across handsets and mobile carriers also bridges the information gap in ante-natal and maternal care.

An assessment showed that over a million women have been reached through various messaging services [42]. Anecdotal feedback suggests that the mobile health information programme is relevant and appropriate in maternal care and has contributed to improving mothers' knowledge on maternal and child health [41,42]. The messaging service developed under the MAMA programme has also been integrated into the national health messaging architecture on maternal and child health. Such integration (one of the few identified in our study) enhances the sustainability of the intervention.

\section{Multi-country Social Media Programme for Youth on Sexual and Reproductive Health (SRH)}

Demographically, young people constitute the highest population group in Africa, but they are faced with widespread needs for information, skills and services for their sexual and reproductive health. A global report [4] argues that sub-Saharan Africa's adolescent birth rates remain the worlds highest, with a regional average of 120 compared to the developing world average of 85 . Less than 15 per cent of women aged 15-19 report current condom use, and less than 5 per cent report condom use in most countries in sub-Saharan Africa. Girls report a less than 10 per cent use of a modern contraceptive method. These and other SRH issues require significant youth mobilisation through diverse platforms such as social media [43]

In the last ten years, Marie Stopes, a US-based institution, has been promoting sexuality education through SMS for youth across the continent. According to Williamson [44], the models include one-tomany SMS, one-to-one SMS, and an automated two-way information quiz. Sims service locator and mobile phone voucher programme form a part of the communication's package. An assessment of the intervention suggests mixed results. While it provided information at scale, it observed that knowledge and information sharing did not necessarily translate into behaviour change. The study concluded that mhealth communication should not be considered as a "silver bullet" for all the barriers to SRH programming targeting young people [44].

In Kenya, a similar mobile-based messaging campaign, Mobile for Reproductive Health (m4RH), which integrates "Text for Change", has been running in the country for nearly a decade. Preliminary evaluation indicates that it is a vibrant and powerful platform for mobilizing, engaging with, educating and empowering young people on SRH and HIV [45]. In 2015, another SMS infoline was established by the Family Planning Options (FHOK) to increase sexual and reproductive health information and knowledge among young people [46]. These are two of the numerous E-Health communication solutions for sexuality education and HIV prevention in the country, which have now been extended to other countries in East Africa. Their focus is on messaging and information dissemination on SRH among youth. Ultimately, messaging is expected to lead to discussion of sensitive issues, and finally behaviour change. However, the extent to which this assumption is validated through impact assessment is yet to be convincingly established.

\section{Critical Issues and Discussion}

From our conceptual premise as well as findings from the foregoing case studies, several critical issues that pertain to the deployment of social media for health communication can be identified. In this section, five main themes with implications for the study and practice of communication are examined.

\section{An Avalanche of Social Media Interventions}

It is evident that the increasing levels of internet penetration and the pervasiveness of mobile devices and social networking services have led to the burgeoning of E-Health communication in Africa. These include a wide range of platforms, comprising (i) networking 
sites such as Facebook, YouTube and LinkedIn, etc.; (ii) micro blogging platforms such as Twitter, Wikkis, and (iii) mobile messaging services such Instant Messaging, SMS/MMS. Some of the interventions utilise single media platforms such as Twitter or Facebook, while others adopt multi-media platforms. However, it is argued that integration of social media into existing traditional multi-media communication initiatives is taking place, contrary to earlier findings by [10] which did not observe this trend.

The demographic focus of interventions also varies with the problem being addressed. Although many of them target young people, who are generally perceived as the major users and consumers of digital content, many interventions target other population groups too. Based on the current trend there will be an increase deployment of social media for health outcomes. However, it would be necessary to consider their effectiveness and sustainability. Practical field experience seems to indicate that the deployment of social media for public health delivery is being viewed as another 'pet project syndrome' of development agencies for their branding and visibility. Many of the interventions are branded for specific agencies with limited linkages and coordination. It is thus critical for development institutions to ensure greater coordination of social media programmes to enhance their effectiveness. Strategic alignment of social media interventions will be more impactful rather than the current fragmentary efforts supported by different development agencies. This will ultimately reduce transaction cost and achieve more mileage.

\section{A Flood of Messages}

The overall goal of health communication is multifaceted: addressing the information gap on specific issues, changing social norms and promoting a positive attitude among the target audience. However, the use of social media seems to be more for 'information blast', 'message storm' or 'buzz creation' or 'noise' around specific health issues. Most of the projects attempt to deliver messages, while some focus on group conversation. How such conversation is converted desired behaviour and social change is unclear. Conceptually, social media devices and platforms are largely used for sharing, networking, and connectedness [47]. It is thus essential to underscore the need for a stronger conceptual underpinning of E-Health communication interventions in relation to the pathway to social and behaviour change for different demographics and audience segmentation. While social media platforms are appropriate for message internationality in health education, they may not be particularly effective in addressing underlying structural issues and deep-seated cultural practices. Also, social and behaviour change is a complex process and merely reaching specific individuals with information will not result in behaviour change. To this end, it is critical to consistently apply a theory of change construct to each social media intervention in order to determine their level of social and behavioural outcomes.

\section{Focus on Digital Innovation}

From this study, it is apparent that development agencies have become so enamoured with social media interventions. As demonstrated, the range of application includes mobile phone technology, Thunderclap social media tools and web-based applications for information sharing, connectivity and even for training. Yet, it is apposite to reaffirm the established notion that technology is merely a tool of development and health communication [21,48]. Having the gadget is not the same as using it for health outcomes or for predetermined behaviour by health communicators.

\section{Inequity Amidst Social Media Ubiquity}

Despite the avouched ubiquity of social media, inequities exist on several fronts. Although the reach of digital interventions is significantly higher than the traditional Information Education Communication (IEC) process of engagement, it still has limited coverage and access. Equity issues are not limited to access but to utilisation. A study on young people in Kenya reveals disparities in access and utilisation of social media by young people, consistent with earlier studies [49]. In addition, [50] highlights the issue of exclusion and inequalities in digital communication while $[51,52]$ underscore the need to redress the digital divide that characterises access to and utilisation of digital technology. Thus, for effective utilisation of social media for health communication, an equity-focussed perspective will be critical.

\section{Experts-Driven Interventions}

The role of meaningful participation of critical actors and target audience has been unequivocally raised in development discourse $[53,54]$. But the extent to which their voice is framing social media interventions is uncertain. Thus, for effective social media programming to achieve public health outcomes, a stronger emphasis on the voice of the beneficiaries would be central [55,56]. A shift from needs assessment to rights analysis, coupled with an adjustment from 'information transmission' to 'participatory learning mode', will be desirable. This also assists in eventually changing the narrative of development discourse, which is still currently monopolised by experts.

\section{Enhanced Partnerships}

E-Health communication interventions have clearly demonstrated the power of creative collaboration among different stakeholders such as government institutions, development agencies and the private sector. Many digital service providers in the E-Health communications sphere are mobile phone companies investing in products and solutions to avail the population with health services and health education platforms. Such collaboration has been recognised as indispensable to achieving development outcomes [57]. However, additional strategic thinking around sustainable relationships for public good will enhance the role of the private sector in health communication and overall international development. Also, widening the focus of partnership beyond corporate institutions to networks and communities helps in community E-Health communication approaches.

\section{Conclusion}

Advancements in digital media have led to significant enthusiasm on the use of digital technology for health and development communication. Multiple interventions have been instituted using different social media tools, platforms and devices for health promotion. However, in view of the functional and dysfunctional potentials of social media in society, a pragmatic perspective of their role is necessary.

First, this requires questioning their underlying assumptions and avoiding the tendency toward 'magical effects' syndrome that currently characterises the deployment of social media for public health. While it is important to celebrate the potential and impact of social media in health communication, arrogating "unlimited - uber-effect" to them takes the discourse on media effects back to the era of hypodermic needle model, which is out of tune with reality.

Second, technology is a tool of development not an end in itself Thus, we need to be mindful of a drift toward "new media utopianism" 
or "social media-centricism". As [58] rightfully suggest, it is important to bridge the potential of E-Health communication with its reality in view of challenges associated with limited access, linguistic, cultural and literacy barriers. Therefore, a more pragmatic perspective of the promise and performance of social media technology in health and development programming and a full appreciation of their limitations in health communication are called for.

Third, the author argue for a holistic approach to social media programming in health communication with the leadership of national partners. As currently structured, many of the interventions reflect the interests of various agencies and end up as pilot projects and hobby ideas of such institutions.

\section{Implications for the Study and Practice of Communication}

In view of the relative novelty of the devices, the speed and scale of new social media interventions will likely increase. As a result, communication education in a social media age needs to consider their implications for communications theory, practice, policy, research and training.

i. Theory: Of particular importance is the need to generate and widen theoretical insights on how social media respond to the pathway of change in a social and behavioural context. Media use in health communication is intended to contribute to specific or overall areas of change, such as risk perception, vulnerabilities, individual agency and levels of influence in social change. Thus far, substantial theorising is lacking or weak in the literature. Hence, developing appropriate theories of change for effective grounding of social media interventions is of utmost urgency in maximising the power of social media in health communication.

ii. Practice: A more robust interdisciplinary framework in designing and implementing social media programmes for public health delivery is called for. Health promotion has always required insights from different intellectual domains, but in the digital age, heightened engagement of various professionals is all the more crucial for effective delivery of social media interventions. A wider space for critical users of social media needs to be created for effective design and execution of such programmes. This will also eventually influence the current development discourse, which is still largely driven by experts.

iii. Policy: Systemic policy and programme framework for effective mobilisation of the power of social media for wider development outcomes is paramount. Although many African countries have put in place policies to harness ICT for the continent, they need to respond to the social and behavioural dimensions of the overall health and development context. More investment is needed in E-health communication policy design and implementation from our communications institutions.

iv. Research: Additional research, meta-analyses and analytical studies with strong evaluative and comparative perspectives are necessary to generate evidence for effective programming in this area. After several years of pilot studies, more cutting-edge perspectives and evidence to advance current thinking have become increasing fundamental. The research agenda should include impact and outcomes of interventions and greater hybridization of platforms. More amenable and accessible monitoring and evaluation skills and insights are required for effective e-health communication programming.

Training: Communication institutions need to continuously reinvent their curricular and teaching methodologies to be ahead of the current international development and public health discourse. Courses that integrate informatics, data sciences, epidemiology, social marketing, philosophy, communications and human rights might need to be considered to provide the development industry with inerrant combinations of insights, perspectives and skills. Non-traditional frameworks that connect even disparate domains of knowledge will be necessary in formulating social media programmes for scale and agility in a highly contested and rights-oriented digital world. In essence, a more nimble approach to the study and practice of communication is desperately needed in an ever changing digital world.

\section{References}

1. World Health Organization (2015) Ebola Situation Reports: Cases and Deaths Data up to May 3, 2015.

2. UNAIDS (2011) AIDS at 30: Nations at the Crossroads. UNAIDS, Geneva

3. UNAIDS (2011) UNAIDS Outlook Report 2011. UNAIDS, Geneva.

4. UNICEF (2014) Generation 2030 - Africa.

5. Cooke JG (2009) Public Health in Africa. Center for Strategic and International Studies.

6. Neuhauser L, Kreeps GL (2010) E-health Communication and Behaviour Change: Promise and Performance. Social Semiotics 20: 7-24.

7. USAID (2008) New Media and International Media Development: A Resource Guide for Europe and Eurasia. USAID.

8. Waters JK (2011) The Everything Guide to Social Media. Adams Media

9. Salmon CT, Arkins C (2003) Using Media Campaigns for Health Promotion In: Thompson TL, Dorsey AM, Miller KL, Parrots RL (eds.) Handbook of Health Communication. Routledge Taylor \& Francis Group, Newyork and London. pp: 449-472.

10. de Tolly K, Benjamin F (2011) Mobile Phones: Opening New Channels for Health Communication. In: Waisbord S, Obregon R (eds.) Handbook of Global Health Communication. John Wiley \& Sons, UK. pp: 163-166.

11. Suggs SL, Ratzan SC (2012) Global E-health Communication. In: Waisbord S Obregon R (eds.) The Global Handbook of Health Communication. John Wiley \& Sons, UK. pp: 100-102.

12. Fortuin JB, Molefi M (2003) Telemedicine in South Africa. In: Bodgan Materma (ed.) Advances in Telemedicine and E-health around the World. Medipage, Poland. pp: 9-12

13. Materma B (2006) Advances in Telemedicine and E-health Around the World Medipage.

14. Uimoren P (2012) Social and Mobile Media in ICT4D. In: Braskov RS (ed.) Social Media in International Development Cooperation. Orrecomm at Malmo University and Roskilde University, Denmark.

15. World Health Organisation (2010) An Assessment of E-Health Initiatives in Africa

16. Michael P (2009) The Case for mHealth in Developing Countries. Innovations Technology Governance Globalisation 4: 103-118.

17. West DM (2014) Using Mobile Technology to Improve Maternal Health and Fight Ebola: A Case Study of Mobile Innovation in Nigeria. The Brookings Institution, USA. pp: 1-18.

18. MacPherson Y, Chamberlain S (2013) Health on the Move: Can Mobile Phones Save the World, Policy Briefing.

19. Lefebvre RC (2007) The New Technology: The Consumer as Participants Rather than Target Audience. SMQ 13: 31-42.

20. McNab C (2009) What Social Media offer to Health Professionals and Citizens?

21. Gumucio-Dagron A (2003) What ICT can do for the Rural Poor? Presented at the Conference on Fighting Rural Poverty: The Role of ICT.

22. Balancing Act (2014) The Sub-Saharan Africa Media Landscape.

23. Carmody P (2012) The Informationalisation of Poverty in Africa? Mobile Phones and Economic Structure. Information Technologies and International Development 8: 1-17. 
Citation: Fayoyin A (2016) Engaging Social Media for Health Communication in Africa: Approaches, Results and Lessons. J Mass Communicat Journalism 6: 315. doi: 10.4172/2165-7912.1000315

24. Sey Araba (2011) New Media Practices in Ghana. Int J Comm 5: 380-404.

25. Jessen W (2008) YouTube as a Source of Health Misinformation.

26. Fayoyin A, Ngwainmbi E (2014) Use and Misuse of Data in Advocacy, Media and Opinion Polls in Africa: Realities, challenges and Opportunities. Journal of Development and Communication Studies 3: 528-545.

27. Wahba M, Roudi-Fahimi F (2012) The Need for Reproductive Health Education in Schools in Egypt. Policy Brief.

28. Fayoyin A (2011) Promoting Children's Rights through the New Media: The Nigerian Experience. J Comm 2: 57-65.

29. Uys P (2009) Africa's Second Communications Revolution. Global-ICT, Number 11. Vodacom Group.

30. Green K, Girault P, Wambugu S, Clement N, Adams B (2014) Reaching Men who have Sex with Men through Social Media: A Pilot Intervention. Digital Culture and Education 6: 208-213.

31. Oxfam (2015) Using Mobile Phones for Polio Prevention in Somalia.

32. Carter M (2014) How Twitter May have helped Nigeria contain Ebola. BMJ 369: 96946.

33. Ugwu P (2014) Nigeria Uses Android App and Social media to Fight Ebola

34. Sabin L, Beard J, Agyarko-Poku T, Bachman DeSilva M, Green K, et al. (2013) Exploring the Beliefs, Attitudes, and Behaviours of MSM Engaged in Substance Use and Transactional Sex in Ghana.

35. Young S (2014) Social Media Technologies for HIV Prevention Study Retention Among Men who have Sex with Men (MSM). AIDS Behaviour 18: 1625-1629.

36. Young S, Jaganath D (2013) Online Social Networking for HIV Education and Prevention: A Mixed Methods Analysis. Sexual Transmission Diseases 40: 162-167.

37. Young S, Cumberland W, Lee SJ, Jaganath D, Szekeres G, et al. (2013) Social Networking Technologies as Emerging Tools for HIV Prevention: A Cluster Randomised Trial. Ann Intern Med 159: 318-324.

38. McDonnell M (2014) Kim Green from FHI360 Ghana on Engaging Youth on HIV via Social Media.

39. WHO and UNICEF (2013) Joint Strategic Plan for the Polio Outbreak Response in the Horn of Africa.

40. Davie L (2013) MAMA puts Power in Moms Hands.

41. Lewis K (2014) African Moms go Digital for Better Health Care.
42. Cheers I (2015) In South Africa, Using Mobile Technology to Improve Maternal Health Access.

43. Praekelt G (2012) Using Mobile Social Networks to Stimulate SRH Service and Uptake: The Case of Young Africa Live.

44. Williamson J (2013) SMS 4 SRH Brief: Barriers to Youth Access of Sexuality Reproductive Health Information and Potential mHealth Solution.

45. Namirembe E, Hoefman B (2012) Promoting Youth Reproductive Health through Text Messaging

46. International Planned Parenthood Federation (2015) FHOK Launches SRH SMS Infoline.

47. Christakis N, Fowler J (2011) Connected: The Amazing Power of Social Networks and How They Shape our Lives. Harper Press, London.

48. Mefalopus P (2008) Development Communication Sourcebook: Broadening the Boundaries of communication. The World Bank, Washington.

49. Galperin H, Mariscal J (2007) Digital Poverty: Latin America and Caribbean Perspectives. IDRC Books

50. Castells M (2009) Communication Power. Oxford University Press.

51. Obregon R (2012) Social Media and Communication for Development: Towards an Equity Perspective. In: Braskov RS (ed.) Social Media in International Development Cooperation. Orrecomm at Malmo University and Roskilde University, Denmark

52. Granvist M (2005) Assessing ICT in Development: A Critical Perspective. In Hemer O, Tufte T (eds.) Media and Global Change, Glasco and Nordicom. pp:285-296.

53. Chambers R (2003) Whose Reality Counts: Putting the First Last. Intermediate technology Publications.

54. Easterly W (2014) The Tyranny of Experts. Basic Books, New York.

55. Kothari U (2001) Power, Knowledge and Social Control in Participatory Development. In: Cooke B, Kothari U (eds.) Participation: The New Tyranny? Zed Books, London.

56. Jonnson U (2003) Human Rights Approach to Development Programming UNICEF, Nairobi.

57. United Nations Development Programme UNDP (2006) Partnering for Development: Making it Happen. UNDP, New York.

58. Neuhauser L, Kreeps GL (2003) Rethinking Communication in the E-health Era. J Health Psychol 8: 1-23. 